\title{
Survey on Mathematics Anxiety of Junior Middle School Students
}

\author{
Guiping Yuan \\ School of Educaiton, Linyi University, Linyi(276005), Shandong Province China \\ yuanguiping2004@126.com
}

\begin{abstract}
Objective To investigate difference of mathematics anxiety in gender and grade of junior middle school students. Methods Totally 380 students from 3 junior middle school of Shandong province attended the investigation. The Mathematics Anxiety Scale for Middle School Student used in the investigation was developed by ourselves. Results There is no significant difference in gender and grade on the whole scale. But, there is significant difference in gender on the subscale of exam result anxiety, and in grade on subscale of classroom anxiety. Conclusion The higher level of mathematics anxiety of girls comes from the fact that girls are less confident in learning mathematics. Students of junior three has higher level of classroom anxiety than students of junior one, from which we can get that students may feel the instructional content is a little difficult for them.
\end{abstract}

Index Terms - junior middle school students, mathematics anxiety, efficacy

\section{Introduction}

With the development of the society, the intensifying of all kinds of competition and some problems existing in education of family and school, elementary and middle school students in our country are suffering from different levels of psychological problems, such as learning pressure, interpersonal barriers and loneliness tendency, etc. Among the problems, the academic pressure is the most common. When children troubled by the pressure, often they present anxiety . It is the primary problem which is affecting students' mental health. Mathematics is one of the most important subjects of the primary and middle school students. Mathematic anxiety is a special subject anxiety. In practice, students with mathematic anxiety often are characterized by feeling afraid of math, the mood of fear math and the behavior of avoiding math, thus math grades of high mathematics anxiety students are low generally. At the same time, math anxiety makes individuals produce negative physiological reaction to mathematics stimulation. They often hold wrong belief and a negative attitude for their ability to solve mathematical problems.

Mathematics anxiety in students indicates that its onset coincides with early years of schooling. This could in part be due to social learning from parents and teachers with mathematics anxiety or negative perceptions of math. Parents or teachers might give children mixed messages about mathematics. They might emphasize how highly difficult mathematics is and at the same time tell them how mathematics skills are of essential importance for their future achievements. Vann observed that mathematics anxiety in mothers was significantly predictive of mathematics anxiety in children. This could be so for excessive expectations as well.
As pointed out by Geçtan children of parents with excessive expectations whose love and acceptance is conditional to how well children live up to these expectations have high degree of anxiety. These circumstances might lead to self-consciousness about one's performance and to anxiety arising from not living up high standards of parents. Children's excessive self-critical attitude might cause anxiety disproportionate to their failure in living up to these expectations. In fact, studies do show that low self-esteem, confidence and efficacy are closely related to mathematics anxiety.

Mathematics anxiety may be caused by many factors. It may be caused by negative mathematics experiences, lack of parental encouragement, negative attitudes, lack of self-esteem and confidence, classroom environment, and teaching approach. Consequently, students who experience mathematics anxiety often perform poorly in mathematics related situations.

Poor performance in mathematics has been linked to an increase in mathematics anxiety. Belief and expectations to perform poorly on mathematics problems could also lead to mathematics anxiety or intensify students' existing anxiety. Mathematics anxiety can be experienced to such a degree that children might perceive their performance in mathematics as a measure of their self-worth and a reason for losing value in the eyes of parents and teachers. Thus, students with these excessive worries develop negative attitudes toward mathematics which are expressed as "I can't do mathematics" or "I hate mathematics." However, since they do have to deal with mathematics, these beliefs lead to a great deal of distress and unease.

MA can develop in the early school years and becomes increasingly common with age. It is thought to affect a notable proportion of the school age population and adults in postsecondary education. Importantly, MA has several negative effects on children's and adult's mathematics education. For example, people who experience high levels of MA are likely to develop negative attitudes toward tasks involving mathematics, drop out of elective mathematics classes or avoid taking them altogether; in addition, those with high MA avoid pursuing careers that require quantitative skills. This can have large-scale implications. For example, only $7 \%$ of pupils in the UK take mathematics to A level, and while there are many reasons for this, many pupils give a dislike of mathematics as a reason for not continuing and sometimes the dislike is very intense and 'charged with emotion'.

Math anxiety kids may avoid environment and occupation which needs applying mathematics skills. This is a problem 
we need to solve urgently how to guide students with math anxiety easily develop an affinity for mathematics learning. So it is important that we study the math anxiety to seek a way to reduce or eliminate students' math anxiety. The study also has significance for improving the effect of mathematics teaching and the quality of students mathematics study to promote students healthy development.

\section{Participants and Method}

\section{A. Participants}

400 junior middle school students from Linyi were studied in total. They were random sampling. 20 pupils were excluded from the investigation because they did not fill in the Mathematics Anxiety Scale. We decided to exclude the 20 pupils who did not fill out the mathematics test because it was hard to decide whether they did so because they were not motivated to respond to the questions. The remaining 380 children (191 boys and 189 girls) were included in the sample.

\section{B. Method}

The Mathematics Anxiety Scale was used to measure levels of mathematics anxiety. This was developed based on the results of foreign research and open-ended questionnaire. We assessed its reliability by computing Cronbach's alpha and split-half reliability in our own sample. Cronbach's alpha was 0.92 , split-half reliability was 0.92 . We got five dimensions by factor analysis. They were results anxiety, examination anxiety, classroom anxiety, problem solving anxiety and application anxiety. These values can be considered good. Hence, the questionnaire was reliable.

Using the method of centralized Surveying, we completed sampling work in 1 week. Moreover, we used SPSS 12.0 for data analysis.

\section{Statistics}

Our main interest was to examine the level mathematics anxiety of middle school students. Hence, the data was run on descriptive statistics. Then $\mathrm{T}$ tests were run on each group in gender. Analysis of Variance were run on each dependent grades. Pearson correlations were computed with mathematics anxiety and achievement.

\section{Results}

The overall level of mathematics anxiety

TABLE 1 The overall level of mathematics anxiety

\begin{tabular}{|c|c|c|c|c|c|c|}
\hline Variables & $\begin{array}{c}\text { Total } \\
\text { score }\end{array}$ & $\begin{array}{c}\text { results } \\
\text { anxiety }\end{array}$ & $\begin{array}{c}\text { examination } \\
\text { anxiety }\end{array}$ & $\begin{array}{c}\text { classroom } \\
\text { anxiety }\end{array}$ & $\begin{array}{c}\text { problem } \\
\text { solving anxiety }\end{array}$ & $\begin{array}{c}\text { application } \\
\text { anxiety }\end{array}$ \\
\hline M & 80.72 & 23.4 & 18.51 & 6.42 & 5.56 & 7.94 \\
\hline SD & 22.413 & 7.172 & 6.956 & 3.112 & 2.795 & 3.271 \\
\hline
\end{tabular}

As shown by table1, the overall level of mathematics anxiety are displayed. The score of results anxiety is highest in these five dimensions. This shows that the students pay more attention to the results of learning rather than learning. In addition, the score of examination anxiety is also higher than other dimensions. This shows that the test anxiety of students is obvious.

Gender differences in mathematics anxiety of students

TABLE 2 Gender differences in mathematics anxiety of students

\begin{tabular}{|c|c|c|c|c|c|}
\hline \multirow{2}{*}{ Dimensions } & \multicolumn{2}{|c|}{ boys $(\mathrm{n}=191)$} & \multicolumn{2}{l|}{ girls $(\mathrm{n}=189)$} & $\mathrm{t}$ \\
\cline { 2 - 6 } & $\mathrm{M}$ & $\mathrm{SD}$ & $\mathrm{M}$ & $\mathrm{SD}$ & \\
\hline results anxiety & 22.67 & 7.142 & 24.14 & 7.145 & $-2.013 *$ \\
examination anxiety & 18.65 & 7.212 & 18.37 & 6.705 & 0.397 \\
classroom anxiety & 6.47 & 3.189 & 6.36 & 3.040 & 0.322 \\
problem solving anxiety & 5.77 & 3.017 & 5.36 & 2.543 & 1.433 \\
application anxiety & 7.95 & 3.435 & 7.93 & 3.106 & 0.076 \\
Total score & 80.29 & 23.594 & 81.15 & 21.206 & -0.375 \\
\hline
\end{tabular}

Using gender as a variable, the independent samples $\mathrm{T}$ test was run on math anxiety of students. From table 2, the score of mathematics anxiety is not different between girls and boys on the whole. But from every dimension, the score of results anxiety is different between girls and boys. This shows that girls worry about exam results significantly higher than boys. Grade differences between mathematics anxiety of students

TABLE 3 Grade differences in mathematics anxiety of students

\begin{tabular}{|c|c|c|c|c|c|c|c|}
\hline \multirow{2}{*}{ Dimensions } & \multicolumn{2}{|c|}{$\begin{array}{c}\text { the first grade } \\
(\mathrm{n}=130)\end{array}$} & \multicolumn{2}{|c|}{$\begin{array}{c}\text { the second } \\
\text { grade } \\
(\mathrm{n}=135)\end{array}$} & \multicolumn{2}{|c|}{$\begin{array}{c}\text { the third } \\
\text { grade } \\
(\mathrm{n}=115)\end{array}$} & F \\
\cline { 2 - 7 } & $\mathbf{M}$ & SD & $\mathbf{M}$ & SD & M & SD & \\
\hline results anxiety & 22.90 & 7.708 & 24.26 & 6.527 & 22.95 & 7.235 & 1.517 \\
examination anxiety & 18.47 & 7.336 & 18.86 & 6.755 & 18.15 & 6.787 & 0.326 \\
classroom anxiety & 5.98 & 2.531 & 6.36 & 3.006 & 6.96 & 3.716 & $3.091 *$ \\
problem solving anxiety & 5.34 & 2.574 & 5.46 & 2.641 & 5.93 & 3.175 & 1.482 \\
application anxiety & 8.00 & 3.086 & 7.90 & 3.323 & 7.92 & 3.436 & 0.031 \\
Total score & 79.50 & 22.901 & 81.83 & 21.475 & 80.79 & 23.049 & 0.359 \\
\hline
\end{tabular}

Using grade as a variable, the analysis of variance was run on math anxiety of students. From table 3, the score of mathematics anxiety is not different between grades on the whole. But the second grade of students' anxiety level is the highest. From the dimensions of mathematics anxiety, there is a significant difference between three grades in the classroom anxiety. There are no significant differences in other dimensions of mathematics anxiety. Through post hoc multiple comparisons, the third grade students' classroom anxiety level is significantly higher than first grade. There is no significant difference between other grades.

Correlation analysis of mathematics anxiety and achievement

TABLE 4 Correlation analysis of mathematics anxiety and achievement

\begin{tabular}{|c|c|c|c|c|c|c|}
\hline & $\begin{array}{c}\text { results } \\
\text { anxiety }\end{array}$ & $\begin{array}{c}\text { examination } \\
\text { anxiety }\end{array}$ & $\begin{array}{c}\text { classroom } \\
\text { anxiety }\end{array}$ & $\begin{array}{c}\text { problem } \\
\text { solving } \\
\text { anxiety }\end{array}$ & $\begin{array}{c}\text { application } \\
\text { anxiety }\end{array}$ & $\begin{array}{c}\text { Total } \\
\text { score }\end{array}$ \\
\hline $\begin{array}{c}\text { Mathematics } \\
\text { achievement }\end{array}$ & $-.111^{*}$ & $-.334 * *$ & $-.374 * *$ & $-.369 * *$ & $-.253 * *$ & $-.351 * *$ \\
\hline
\end{tabular}


Correlation analyses established that mathematics anxiety is negatively correlated with mathematics achievement. Five dimensions of mathematics anxiety are negatively correlated with mathematics achievement (See this relationship in table 4).

\section{Discussion}

We found that the scores of results anxiety and examination anxiety are higher than other dimensions. We think that school education and family education is the mainly cause of this phenomenon. In the school, the teachers evaluate students according to their scores. Teachers always praise students who obtain a high score. In the family, parents hope that test scores are higher than the actual capacity. They pay more attention to the examination scores. It increases the students' psychological pressure. Hence, the scores of results anxiety and examination anxiety are higher than other dimensions. Educators should pay more attention to students' test anxiety. These pressures may include parental influence, satisfying prerequisites for future courses, large class, and difficult course content.

We can conclude from table 2, there is no significant difference between boy's and girls's mathematic anxiety. It is consistent with investigation that started in the late 1990s. And it is also consistent with the conclusion of latest international comparative study which shows there is no significant difference between boy's and girl's anxiety in china primary school grade 6 . The reason that there is no significant difference between boy's and girl's mathematic anxiety may stem from the fact that the positive impact on educator and educatee produce by the actual condition of china the policy and the guidance of public opinion of equality between man and women. The positive impact would improve female leaner's learning confidence and would eliminate the inherent gender bias. So, in order to reduce student's mathematic anxiety we should pay attention to and improve their social and cultural background, and should be tolerant to and be equal to every student.

In addition, we also can explore the reason of there is no significant difference between boy's and girl's mathematic anxiety from the gender characteristics of junior school students mathematical ability. The traditional classification of basic mathematic abilities is calculating ability, space imaginative power and abstract thought. Result of many previous research indicate that there is difference between boy's and girl's calculating ability, space imaginative power and logical thinking ability on average leve. But the difference is not significant. From above statement, we can conclude that the gender difference is not significant, boys and girls have the same ability on learning mathematics, this may be the reason why there is not significant difference between boy's and girl's mathematics anxiety.

Table 2 indicates that there is significant difference on the dimension of test result anxiety. The level of girl's anxiety is higher than boy's. The reason may come from that girl's confidence of learning mathematics is not as good as boy's.
Although girls have enough ability to learn mathematics, but still full of worries, so showed higher level test result anxiety. Overall, girls reported higher levels of MA than boys, supporting our hypothesis. This finding is in line with the many other studies cited in the Introduction that found higher levels of MA in females than males, though as noted there such findings are not universal.

The reason for why females frequently report higher MA than males is not well understood but several explanations have been offered. Some have suggested that the different ways in which boys and girls are socialized during childhood may differentially affect the anxiety experienced by males and females in certain situations. This hypothesis, known as the sex-role socialization hypothesis, argues that because mathematics is traditionally viewed as a male domain, females may be socialized to think of themselves as mathematically incompetent and therefore females may avoid mathematics and when females do participate in mathematical activities they may experience more anxiety than males. However, no link between MA and sex-role has been found and the view that mathematics is a male domain is decreasing. Therefore, this hypothesis is unlikely to explain effects fully.

From table 3 we can conclude that there is no significant grade difference. However graph 1 shows that level of mathematics anxiety changes with grade. The total level of mathematics offers firstly upgrade than descending latter tendency, and the top point come in the second year. This is not consistent with our hypothesis.

We assume that the top point come in the third year, because in this year student will face the pressure of middle school entrance exam. However our study show that there is not significant grade difference, so we can say that the development of mathematics anxiety is stable relatively. And from the general tend the highest point of mathematics anxiety level comes in the second year, we think this may be related to that the second year is the critical period and transition period of the junior middle school stage and facing special problems related to the physical and mental development, students' problems in general are more concentrated in this period.

Grade two is a crucial stage for the student of junior high school. During the period student has proceed with a trend that there exits unbalanced quality among student talents. Some student had a hard time in math study, it can turn out to be a tremendous burden. So student's mathematics anxiety will upgrade. Overall, during grade 2 of junior high student's mathematics anxiety level is relatively higher.

The students' interest in learning mathematics will affect the level of mathematics anxiety. According to research, The higher grade, the lower of students' interest in mathematics. It shows that the second grade students' interest in learning mathematics is lower than other grades, so it proves there is a higher math anxiety level of the second grade. It indicates that students with higher mathematics anxiety have lower mathematics interest. Hence, we can enhance the students' interest in learning mathematics to reduce students' anxiety level. 
From table 3 , there is a significant difference between grades in classroom anxiety and the classroom anxiety of the third grade is highest. A possible explanation for this phenomenon is that the third grade of students should master more knowledge than other grades and the mathematics knowledge of the third grade is more complex than other grades. The students of the third grade are suffering the pressure of entering a higher school.

Results showed that the students' mathematics anxiety differed significantly according to their level of achievement in mathematics. The higher their achievement level the lower was their mathematics anxiety. Working with samples of elementary school students, Lafferty and Miller also found that those with higher achievement in mathematics had lower degrees of anxiety for mathematics. Norwood, Ma and $\mathrm{Xu}$ and Yüksel-Şahin, found confirming results with high school students. Other studies also found parallel results indicating a negative relationship between achievement in mathematics and anxiety about math. Townsend et. al. reason that low achievement increases students fear and anxiety about mathematics which in turn negatively impacts achievement.

\section{Conclusions}

Our study has revealed that Junior Middle School Students experience mathematics anxiety. The scores of results anxiety and examination anxiety were higher than other dimensions. The score of mathematics anxiety is not different between girls and boys on the whole. But from every dimension, the score of results anxiety is different between girls and boys. The score of mathematics anxiety is not different between grades on the whole. But the second grade of students' anxiety level is the highest. Correlation analyses established that mathematics anxiety is negatively correlated with mathematics achievement. Five dimensions of mathematics anxiety are negatively correlated with mathematics achievement. These results might suggest that we should pay attention to students' mathematics anxiety and girls may have had the potential to perform better than boys in mathematics however their performance may have been attenuated by their higher levels of mathematics anxiety.

\section{References}

[1] Richardson, F., C., \& Suinn, R., M. The mathematics anxiety rating scale: psychometric data. Journal of Counseling Psychology, 1972, 19(6): 551-554.

[2] Suinn, R., M. \& Edwards, R. The measurement of mathematics anxiety: The Mathematics Anxiety Rating Scale for adolescents-MARS-A. Journal of Clinical Psychology, 1982, 38(3): 576-580.

[3] Cemen, P., B. The nature of mathematics anxiety. (Report No. SE 048689). 1987, Stillwater, OK: Oklahoma State University. (ERIC Document Reproduction Service No. ED 287 729)

[4] Yifeng Huang, Pi Lei. Junior high school students psychology, Zhejiang education publishing house, December, 1993:80.

[5] Chongde Lin. Learning and Development-development and cultivate students' psychological ability. Beijing Normal University Publication Hose, November, 1999:308-324. 